\title{
AGRUPACIONES DE ELECTORES Y LA POSIBLE CONTINUIDAD DE PARTIDOS POLÍTICOS ILEGALIZADOS POR PARTE DE ÉSTAS (Comentario a la STC 68/2005, de 31 de marzo)
}

\author{
M. ${ }^{a}$ ISABEL SERRANO MAÍLLO \\ Profesora Titular interina de Derecho Constitucional \\ Universidad Complutense
}

SUMARIO

I. Una breve aproximación al tema.

II. Partidos políticos, agrupaciones de electores y el problema de su continuidad.

III. El derecho a participar en los asuntos públicos. Derecho al sufragio pasivo.

IV. Una polémica cuestión: la brevedad de los plazos.

V. El derecho a la intimidad en relación con la legislación de protección datos personales.

VI. ¿Qué supone el silencio o la ausencia de condena como respuesta a los atentados terroristas?

VII. Recapitulación: el estado de la jurisprudencia constitucional.

\section{UNA BREVE APROXIMACIÓN AL TEMA}

El problema del terrorismo hace necesario, por parte del Estado y de los Tribunales, una vigilancia exhaustiva para tratar de evitar que los representantes o simpatizantes activos de aquellos grupos que defienden el terror copen parcelas de poder político. Por ello la Ley de Partidos Políticos introdujo, no sin polémica, la posibilidad de ilegalizar aquellas formaciones políticas que, desvirtuando el carácter democrático del proceso electoral y la representación 
política de los ciudadanos, utilizaran los votos de éstos para defender posturas favorables a la violencia ${ }^{1}$ y también a aquellas formaciones que, amparándose en una nueva identidad, trataran de burlar el sistema democrático para poner los votos obtenidos al servicio de aquellos partidos políticos ilegalizados.

El Tribunal Constitucional ya ha tenido ocasión de pronunciarse sobre este tipo de agrupaciones de electores que surgen como meras continuadoras de partidos políticos ilegalizados ${ }^{2}$, como parece ser el caso de Aukera Guztiak, aunque hay que apuntar, no obstante, que no en todos los casos se trataba de agrupaciones "defraudadoras", casos éstos en los que el Tribunal Constitucional reconoció vulnerado su derecho a la participación política y las restableció en su derecho.

En el caso que nos ocupa, la agrupación de electores Aukera Guztiak interpuso Recurso de Amparo contra la sentencia de la Sala del Art. 61 de la LOPJ del Tribunal Supremo, de 26 de marzo de 2005, en la que se anularon, por no considerarse conformes a Derecho, los Acuerdos de las Juntas Electorales de los territorios históricos de Álava, Guipúzcoa y Vizcaya, de 22 de marzo de 2005, de proclamación de las candidaturas presentadas en dichos territorios por la mencionada agrupación. Los recurrentes en amparo alegaron que la STS vulneraba diferentes derechos fundamentales como el derecho a obtener una tutela judicial efectiva (art. 24.1 CE), el derecho de defensa y derecho a la prueba (art. 24.2 CE), el derecho a participar en los asuntos públicos (art. 23.1 CE), el derecho a la libertad ideológica (art. 16.1 CE), el derecho a la intimidad (art. 18.1 CE), el derecho a la libertad de expresión (art. 20.1 CE) y el derecho de asociación (art. 22 CE). El Tribunal Constitucional, en la STC 68/2005, de 31 de marzo, dio respuesta a estas alegaciones y finalmente desestimó el recurso.

$\mathrm{Si}$ bien es cierto que no se trata de una resolución que destaque por la novedad de sus argumentaciones ${ }^{4}$, sí viene a reabrir el debate sobre la legitimidad

1 No se trata de erradicar ningún tipo de ideologías, por incómodas o incompresibles que puedan ser para algunos o para la mayoría, dado que como ya ha repetido el Tribunal Constitucional en sus SSTC 48/2003, de 12 de marzo; 85/2003, de 8 de mayo; 5/2004 y 6/2004, de 16 de enero; y 99/2004, de 27 de mayo, «las ideologías son en el ordenamiento constitucional español absolutamente libres y deben encontrar en el poder público la primera garantía de su indemnidad, a la que no pueden aspirar, sin embargo, quienes se sirven para su promoción y defensa de medios ilícitos o violentos y se sirven de la intimidación terrorista para la consecución de sus fines. Son esos medios y no las ideas o los objetivos políticos pacíficamente perseguidos a los que está destinada la reacción del poder público en defensa del marco de convivencia pacífica diseñado por el constituyente para que en él tengan cabida todas las ideas".

2 Las sentencias del Tribunal Constitucional que ya se refirieron con anterioridad a ese tipo de casos son: STC 176/2003, de 10 de octubre (Herri Taldea); STC 85/2003, de 8 de mayo (Ametzak Amezketa); STC 99/2004, de 27 de mayo (Herritaren Zerrenda), si bien, en las dos primeras, el Tribunal Constitucional determinó que no existía continuidad con partidos ilegalizados anteriormente.

3 Término utilizado tanto por el Tribunal Constitucional como por el Tribunal Supremo en las sentencias a las que nos referimos en este trabajo.

4 La totalidad de los temas que aborda ya fueron tratados en sentencias anteriores - como lo refleja el hecho de que el Tribunal Constitucional nos remita constantemente a algunas de sus resoluciones anteriores. Concretamente a las SSTC 48/2003, 85/2003, 5/2004 y 99/2004 entre otras. 
o no, la conveniencia o no, la constitucionalidad o no de ilegalizar cierto tipo de formaciones políticas 5 . Es más, podemos afirmar que nos encontramos ante una decisión de extraordinaria importancia, puesto que viene a confirmar la jurisprudencia del Alto Tribunal en cuestiones de gran relevancia tanto para el Derecho Constitucional en general como para el Derecho de Partidos en particular. Se trata de cuestiones como la democracia militante ${ }^{6}$, la constitucionalidad de ciertos preceptos de la Ley de Partidos (LO 6/2002) y el fin último de ésta ${ }^{7}$, la importancia de los plazos, la prueba, la participación política, la condena de atentados terroristas y una larga serie de cuestiones a las que nos referiremos en este trabajo.

Hay que advertir que en este comentario se ha tenido en cuenta la jurisprudencia del Tribunal Constitucional sobre cuestiones que, aun no siendo objeto de un análisis detallado en esta sentencia, sí lo han sido en resoluciones anteriores referidas a cuestiones semejantes y, que por su relevancia, consideramos interesante reseñar.

\section{PARTIDOS POLÍTICOS, AGRUPACIONES DE ELECTORES Y EL PROBLEMA DE SU CONTINUIDAD}

Quizás sea conveniente iniciar este comentario haciendo referencia a la dificultad que entraña la equiparación entre partido político y agrupación de electores habida cuenta que de admitirse, cabría la posibilidad de considerar a las agrupaciones meras continuadoras de los partidos y, por ende, ilegalizarlas por esta causa ${ }^{8}$. Ello podría suponer además, una limitación del ejercicio del derecho fundamental al sufragio pasivo?.

5 En este caso, la ilegalización de la agrupación de electores Aukera Guztiak por su supuesta continuación de partidos ilegalizados por su vinculación con grupos terroristas.

6 REVENGA SÁNCHEZ, Miguel, en "El tránsito hacia (y la lucha por) la democracia militante en España”, (en Revista de Derecho Político núm. 62, pág. 13), dice: "Militantes suelen denominarse aquellas democracias que cuentan con medios de defensa para "plantar cara" a quienes aprovechan las posibilidades abiertas por un sistema de libertades para todos, con el fin de intentar destruirlo. (...) La calificación de la democracia como militante no se refiere, sin embargo, a esa clase de defensa genérica. Alude más bien a formas específicas de protección, que actúan en la dirección opuesta a la de un sistema de libertades gracias al cual es posible concebir, expresar, y aspirar a ver plasmado cualquier proyecto político".

7 HERREROS LÓPEZ, Juan Manuel, "Ilegalización y disolución de partidos políticos", en MONTILLA MARTOS, José Antonio (ed.), La probibición de partidos políticos, Universidad de Almería, 2004, pág. 137 dice: "No son pocos los que apuntan que la vigente Ley de Partidos nunca se hubiera dictado de no persistir el problema del terrorismo en España, así como que podríamos estar ante una norma particular o ad casum, pensada para un supuesto concreto: la ilegalización de Batasuna".

8 No hay que olvidar que este Recurso de Amparo trae causa de la STS de 26 de marzo de 2005 , en la que se declararon no conformes a derecho y, por tanto, anulados los actos de proclamación de las candidaturas ahora recurrentes de amparo.

9 En la STC 68/2005, de 31 de marzo, la agrupación recurrente invocó como vulnerado el derecho a participar en los asuntos públicos reconocido en el art. $23 \mathrm{CE}$ alegando que "no hay entre la 
Los partidos políticos ${ }^{10}$, como recoge el Tribunal Constitucional en su sentencia 48/2003, tienen la "doble condición de instrumentos de actuación del derecho subjetivo de asociación ${ }^{11}$, por un lado, y de cauces necesarios para el funcionamiento del sistema democrático, por otro. (...) Se trata de asociaciones cualificadas por la relevancia constitucional de sus funciones ${ }^{12}$; funciones que se resumen en su vocación de integrar, mediata o inmediatamente, los órganos titulares del poder público a través de los procesos electorales" (FJ 5) ${ }^{13}$, pero "la libertad característica de las asociaciones, y de la que los partidos también disfrutan, no puede ser (...) tan omnímoda que a su amparo se desvirtúen como instrumentos para la consecución de sus fines constitucionales ${ }^{14}$.

En cambio, las agrupaciones de electores, según expone el Tribunal Constitucional, además de ser formaciones de naturaleza efímera ${ }^{15}$ y que "responden al designio de (la) espontaneidad" ${ }^{16}$, "no tienen más estructura y organización que las de las agrupaciones que instrumenta y su funcionamiento se reduce al necesario para la presentación de las candidaturas". Son "verdaderos instrumentos de participación política que agotan su sentido en la actualización del ejercicio de sufragio pasivo por parte de los particulares que en ellas se agrupan", por lo que "la similitud entre el partido disuelto y una agrupación de electores es, en principio, imposible. (...) Son términos tan heterogéneos que no cabe la continuidad, salvo, justamente, si la agrupación deja de ser propia-

Agrupación recurrente y los partidos disueltos la "similitud sustancial" exigida por la Ley y, en todo caso, se insiste en la idea de que el art. 44.4 LOREG es inconstitucional por infracción del art. $23 \mathrm{CE}$, ya que con él se priva del derecho de sufragio pasivo a quien participe de una determinada ideología o haya tenido relación en el pasado con un partido legal y luego disuelto". (Antecedentes 3.b).

10 Artículo 6 CE: “Los partidos políticos expresan el pluralismo político, concurren a la formación y manifestación de la voluntad popular y son instrumento fundamental para la participación política. Su creación y el ejercicio de su actividad son libres dentro del respeto a la Constitución y a la ley. Su estructura interna y funcionamiento deberán ser democráticos".

11 STC 3/1981, de 2 de febrero (FJ1) dice: "Un partido es una forma particular de asociación”.

12 Respecto a la función de los partidos políticos, dice la STC 99/2004 (FJ 15): "...uno de los contenidos definidores de la función de los partidos, cual es la integración personal de las instituciones públicas con representantes elegidos de entre las listas partidarias ofrecidas al cuerpo electoral".

13 Continúa este FJ 5: "Conformando y expresando la voluntad popular, los partidos contribuyen a la realidad de la participación política de los ciudadanos en los asuntos públicos (art. 23CE), de la que ha de resultar un ordenamiento integrado por normas que (...) en su contenido material se determinan por el juego de las mayorías que en cada momento respalden las diferentes opciones ideológicas y políticas, conformadas y aglutinadas por los partidos a través de la concurrencia de sus programas de gobierno en los distintos procesos electorales".

14 STC 48/2003 (FJ 6).

15 STC 85/2003 (FJ 25) y 99/2004 (FJ 15) exponen: "Con su prolongación en el tiempo, la agrupación electoral perdería la naturaleza efímera que es común a las agrupaciones de electores y pasaría a asimilarse a un partido político, siendo ya factible apreciar un eventual continuum entre la agrupación y un partido disuelto en el pasado".

16 Como apunta la STS de 26 de marzo de 2005 (FJ 4): "... idea de espontaneidad que ha de caracterizar la aparición de las agrupaciones de electores. El análisis de esta idea de "espontaneidad" ha de considerarse especialmente reveladora a la hora de abordar el juicio sobre la continuidad o sucesión de una agrupación electoral con respecto de un partido ilegalizado". 
mente tal, instrumentalizándose al servicio de la reactivación o continuidad de un partido disuelto" ${ }^{17}$.

Se trata, por tanto, de dos realidades diferentes, "ni equivalentes ni equiparables" ${ }^{18}$ y será en cada caso concreto cuando haya que determinar, como apunta el Tribunal Supremo, si la agrupación de electores "cumple la finalidad propia de su naturaleza o, si, por el contrario, de hecho, y pervirtiendo el sentido de esta figura, ha sido utilizada de forma fraudulenta para conseguir perpetuar en la vida social, política y jurídica la actividad de unos partidos previamente ilegalizados..."19.

No obstante lo dicho respecto a la imposibilidad de equiparar partido y agrupación, y sin olvidar el posible carácter defraudatorio de algunas de éstas, el art. 44.4 LOREG $^{20}$ ha fijado unos criterios para determinar si existe un vínculo entre ambos, que se resume en la existencia de una similitud sustancial entre sus elementos orgánico-funcionales, personales y financieros. Según enumera el propio Tribunal Constitucional ${ }^{21}$ se concretarían de la siguiente manera:

a) Que exista una similitud sustancial de las «estructuras, organización y funcionamiento".

b) Que exista una similitud sustancial de las "personas que los componen, rigen, representan o administran las candidaturas".

17 STC 85/2003 (FJ 25 y ss). En el voto particular formulado en esta sentencia por la Magistrada doña María Emilia Casa Baamonde, haciendo referencia al FJ 24, expone: «las agrupaciones de electores son instrumento directo del ejercicio del derecho fundamental de participación política (art. $23 \mathrm{CE}$ ), a cuyo través ejercen su derecho de sufragio pasivo los ciudadanos que quieren participar directamente en los asuntos públicos sin la mediación de los partidos"

18 Dice la STC 68/2005 (FJ 10): "Nunca se nos han escapado las dificultades que conlleva todo intento de equiparación conceptual entre los partidos políticos y las agrupaciones electorales. Por tratarse de realidades que no son equivalentes, ni siquiera equiparables". En este mismo sentido dice la STC 85/2003 (FJ 24): «Partidos políticos y agrupaciones de electores no son realidades equivalentes; ni siquiera equiparables. Unos y otras son instrumento de participación política. Pero el primero lo es de la participación política de ciudadanos que le son ajenos, en tanto que éstas lo son de los ciudadanos que las constituyen...".

19 STS de 26 de marzo de 2005 (FJ.3), continúa: «... o, dicho de otra manera, si se ha constituido en mero instrumento de unos partidos ilegalizados y disueltos, desvirtuando la finalidad primigenia que tiene toda agrupación electoral como cauce de participación activa de los ciudadanos en la vida política, como pretenden los recurrentes".

20 Art. 44.4 LOREG: «4. No podrán presentar candidaturas las agrupaciones de electores que, de hecho, vengan a continuar o suceder la actividad de un partido político declarado judicialmente ilegal y disuelto, o suspendido. A estos efectos, se tendrá en cuenta la similitud sustancial de sus estructuras, organización y funcionamiento de las personas que los componen, rigen, representan o administran las candidaturas, de la procedencia de los medios de financiación o materiales, o de cualesquiera otras circunstancias relevantes que, como su disposición a apoyar la violencia o el terrorismo, permitan considerar dicha continuidad o sucesión". (Añadido por Ley Orgánica 6/2002, de 27 de junio, de Partidos Políticos.)

21 En la STC 85/2003 (FJ 25), se desglosa el art. 44.4 LOREG y se enumeran las similitudes sustanciales que deben darse entre un partido político disuelto y una agrupación de electores para poder considerar que ésta es continuadora de aquél. Observa el TC, que se trata de las mismas similitudes sustanciales que en el caso de la sucesión de partidos. 
c) Que exista una similitud de la "procedencia de los medios de financiación o materiales".

d) Por último, se tendrán en cuenta "cualesquiera otras circunstancias relevantes que, como su disposición a apoyar la violencia o el terrorismo permitan considerar dicha continuidad o sucesión".

Esos criterios deben emplearse por los Tribunales para determinar si existe continuidad entre un partido político disuelto y una agrupación de electores, siempre teniendo en cuenta que "lo decisivo es que abonen la convicción fundada de que las agrupaciones electorales cuya proclamación se deniega operan materialmente como componentes constitutivos de un partido de facto y no como verdaderos instrumentos de participación política que agotan su sentido en la actualización del ejercicio del derecho de sufragio pasivo por parte de los participantes que en ella se agrupan"22. A este respecto comenta el Tribunal Constitucional, en sus sentencias 99/2004 y 68/2005: “...de lo que en el proceso $a$ quo se ha tratado ha sido solo de impedir la continuidad de unos partidos declarados ilegales por Sentencia firme. Quienes, relacionados en el pasado con esos partidos, quieran 'reconstruirlo' fraudulentamente con ocasión de sucesivas convocatorias electorales deben contar con el riesgo cierto de que aquella vinculación pueda, pero siempre en unión de otros indicios, erigirse en factor determinante de una convicción judicial que lleve a dar aplicación a la norma contenida en el art. 44.4 LOREG. Quienes, por el contrario, con esos mismos antecedentes decidan ejercer su derecho de sufragio pasivo sin instrumentalizarlo al servicio de aquella maniobra defraudatoria no habrá de tener, como no la han tenido (...), otras personas, dificultad alguna para articular candidaturas en otros partidos o para construir las pertinentes agrupaciones de electores" ${ }^{23}$.

Podemos concluir, por lo tanto, que lo que el legislador ha querido evitar con este polémico art. 44.4 LOREG es que una agrupación de electores pervierta su naturaleza con el fin de constituirse en el instrumento necesario que dé continuidad material a un partido ilegalizado, provocando que las diferencias que median entre estas dos realidades "conceptualmente inconfundibles" se diluyan y puedan llegar a ser equiparables y, por tanto, continuadora aquélla de éste ${ }^{24}$.

22 SSTC 85/2003 (FJ.26) y 68/2005 (FJ 11).

23 SSTC 99/2004 (FJ 19) y 68/2005 (FJ 16).

24 STC 68/2005 (FJ 10) dice: "Quiere esto decir que toda la distancia que media entre ambas categorías se diluye, precisamente, cuando la naturaleza propia de las agrupaciones electorales se pervierte con el fin de constituirlas en instrumentos para la continuidad material de un partido, operando así el ánimo defraudatorio como la solución de continuidad necesaria entre dos realidades conceptualmente inconfundibles. Y al es justamente el efecto que con el art. 44.4 LOREG ha querido evitar el legislador orgánico". 


\section{EL DERECHO A PARTICIPAR EN LOS ASUNTOS PÚBLICOS. DERECHO AL SUFRAGIO PASIVO}

El derecho al sufragio pasivo, según lo definió el propio Tribunal Constitucional en su STC 85/2003 (FJ 29), es un derecho constitucionalmente relevante $^{25}$, pero "en la medida en que una agrupación electoral se articule (...) al servicio de un fin defraudatorio, su equivalencia funcional con el partido disuelto debe imponerse a toda otra consideración, también a la del ejercicio de un derecho que, así instrumentalizado, se pervierte en tanto que derecho" ${ }^{26}$.

Es jurisprudencia reiterada del Tribunal Constitucional, al contrario de lo que alega la parte recurrente en amparo, que la ilegalización de un partido político no tiene como consecuencia la privación del derecho de sufragio (ni activo ni pasivo) a ningún ciudadano. Sólo un procedimiento judicial contra una persona concreta, a causa de sus actos o conducta y en los términos que establece la ley, puede tener como consecuencia la privación del derecho fundamental al sufragio ${ }^{27}$.

El Alto Tribunal advierte, además, que "las personas que figuran en una agrupación no proclamada pueden ejercer su derecho de sufragio pasivo a través de otra candidatura" ${ }^{28}$, si bien es cierto, como él mismo reconoce, que aunque no se restringe el derecho ni se excluye de forma absoluta, lo que sí se impide es que "lo disfruten en unión de quienes con su concurso puedan dar fundamento razonable a la convicción judicial de que se está ante un concierto de voluntades para la elusión fraudulenta de las consecuencias jurídicas la disolución de un partido político" ${ }^{29}$.

25 STC 68/2005 (FJ 11) reitera la jurisprudencia sentada en su STC 85/2003 (FJ 29), cuando dice: "En definitiva, estando en juego la efectividad del ejercicio de un derecho fundamental, este Tribunal Constitucional, ponderando los derechos individuales en presencia y el interés general del ordenamiento en la sujeción de los procedimientos electorales al principio de legalidad debe verificar aquella revisión con arreglo a un canon decisorio cuyo contenido ha de depender de la apreciación conjunta de una pluralidad de magnitudes y referencias que permitan inferir, de modo razonable y no arbitrario, que la agrupación electoral excluida del proceso ha actuado, de hecho, como continuadora de la actividad de los partidos ilegalizados".

26 STC 85/2003 (FJ 26) continúa: “Como es evidente, el sacrificio del derecho de los ciudadanos a concurrir a un proceso electoral a través de una agrupación de electores pasa por el pronunciamiento judicial de que la agrupación constituida sirve realmente a la consecución de un fin que no es el del ejercicio de aquel derecho, sino el de la elusión de los efectos de la disolución de un partido político".

27 STC 68/2005 (FJ 10) reitera la jurisprudencia sentada en sus SSTC 85/2003 y 99/2004 (FJ 23) y apunta al respecto que "la disolución de un partido político o comporta la privación del derecho de sufragio, activo o pasivo, de quienes fueron sus promotores, dirigentes o afiliados. Semejante consecuencia solo puede traer causa de procedimiento judicial específicamente centrado en la conducta o en las circunstancias de personas físicas, quienes, en los términos previstos por la ley, únicamente pueden verse privadas del ejercicio del derecho fundamental reconocido en el art. 23.1 CE si concurren las causas también taxativamente fijadas por el art. 6 de la Ley electoral, entre las que no figura la vinculación con un partido disuelto en aplicación de la Ley Orgánica 6/2002".

28 SSTC $85 / 2003$ (FJ 24) y 68/2005 (FJ 10).

29 SSTC 99/2004 (FJ 14) y 68/2005 (FJ19). 
No se trata, por tanto, de restringir un derecho fundamental, sino de establecer una serie de "mecanismos de garantía institucional "30 para evitar que las agrupaciones de electores pierdan su naturaleza de formaciones para la participación política y se conviertan en organizaciones fraudulentas que, bajo el disfraz de democráticas sólo tengan como fin la continuidad de un partido ilegalizado pudiendo, así, traicionar la verdadera naturaleza del derecho al sufragio pasivo ${ }^{31}$. En este mismo sentido se pronuncia el Tribunal Supremo al considerar que la exclusión del proceso electoral de este tipo de agrupaciones fraudulentas "no implicará, en absoluto, una vulneración del derecho de sufragio pasivo de aquellas personas que, en principio, gozarían de capacidad o aptitud individual para ser elegidos por no haber sido declarada formalmente restricción alguna de sus derechos civiles fundamentales de participación política, pero que han de verse necesariamente afectadas por la limitación legítimamente establecida por el legislador para salvaguardar principio esenciales de nuestro sistema democrático, ${ }^{32}$.

\section{UNA POLÉMICA CUESTIÓN: LA BREVEDAD DE LOS PLAZOS}

En la sentencia comentada se plantean diferentes cuestiones de carácter procesal que, si bien no son específicas de nuestra disciplina, creo interesante comentar, aunque sea brevemente, por la atención que les prestan tanto el Tribunal Supremo como el Tribunal Constitucional.

De todas ellas, la más debatida y a la que el Tribunal Constitucional se ha referido ya en las sentencias anteriores relativas a los procesos electorales, es la posible inconstitucionalidad del art. 49 de la LOREG debido a la brevedad de los plazos que establece para resolver el proceso contencioso-electoral. Este plazo es de dos días para la interposición de recursos y dos para la resolución judicial "que habrá de dictarse en los dos días siguientes a la interposición del recurso". Además "el amparo debe solicitarse en el plazo de dos días y el Tribunal Constitucional debe resolver sobre el mismo en los tres días siguientes".

30 Vid. supra notas anteriores.

31 STC 85/2003 (FJ 25), refiriéndose al art. 44.4 LOREG, dice: "No atiende a cualesquiera agrupaciones electorales, sino específicamente a las que sirven de instrumento para la evasión fraudulenta de las consecuencias de la disolución de un partido político. En definitiva, las agrupaciones electorales que, de hecho, y pervirtiendo la naturaleza y sentido de la institución, se quieren antes elementos constitutivos de un nuevo partido que instrumento de ejercicio del derecho de sufragio pasivo por parte de los ciudadanos al margen de la disciplina partidista".

32 El Tribunal Supremo en su STS de 26 de marzo de 2005 (FJ 7), refiriéndose a lo ya pronunciado en sus sentencias de 3 de mayo de 2003 y de 21 de mayo de 2004 dice: "ninguna duda cabe albergar de que la Ley Orgánica 6/2002 de 27 de junio de Partidos Políticos (...) respeta el contenido esencial del derecho de acceso a los cargos públicos consagrado en el art. 23.2 de la CE en la medida en que se limita en su articulado a impedir que puedan concurrir a un proceso electoral agrupaciones de electores que de hecho intenten continuar suceder a actividad de un partido político judicialmente ilegalizado disuelto" 
Tanto el Tribunal Constitucional como el Tribunal Supremo reconocen la dificultad que supone tratar de resolver este tipo de cuestiones en tan escaso tiempo, pero a la vez estiman que no puede ser de otro modo, dado el carácter especial que tienen los procesos contencioso-electorales, que exige una gran celeridad con el fin de que se desarrollen dentro de los plazos establecidos. En este sentido, dice el Alto Tribunal en su STC 68/2005 (FJ 4):

«Este Tribunal no ha desconocido, ni puede ahora desconocer, la dificultad de insertar un supuesto tan complejo como el contemplado en el art. 44.4 LOREG en el proceso contencioso-electoral que regula su art. 49, caracterizado por las notas de celeridad, perentoriedad, preclusión de plazos y concentración de las fases de alegaciones y prueba. Notas que, como ya hemos declarado, han de considerarse constitucionalmente necesarias y proporcionadas en cuanto responden a la finalidad razonable de que el proceso electoral se desarrolle efectivamente en el plazo legalmente establecido (SSTC 48/2000, de 24 de febrero, FJ 3; 85/20003, de 8 de mayo, FJ 10). Ahora bien, ante la aludida complejidad del supuesto contemplado en el art. 44.4 LOREG, en el que se trata de dilucidar si la candidatura o candidaturas presentadas por una o varias agrupaciones electorales vienen de hecho a continuar o suceder la actividad de un partido político declarado judicialmente ilegal y disuelto o suspendido, sería deseable un especial esfuerzo por parte del legislador en orden a lograr un mejor acomodo procesal para este tipo de supuestos".

En la citada sentencia el Tribunal Constitucional, pues, reconoce que los plazos son muy breves, dado que se dispone de muy poco tiempo para resolver los recursos presentados ante el Tribunal Supremo y, posteriormente, presentar la demanda de amparo constitucional, pero a la vez considera que estas limitaciones están dentro de lo constitucionalmente necesario y proporcionado. Más adelante pone de manifiesto que la parte recurrente tuvo tiempo suficiente, puesto que hizo las impugnaciones que consideró pertinentes, formuló alegaciones al respecto y propuso los medios de prueba que estimó convenientes ${ }^{33}$.

Sobre la polémica relativa a la inconstitucionalidad del art. 49 LOREG, el Tribunal Constitucional ya se había pronunciado en sentencias anteriores, en el sentido de que la brevedad de plazos no afecta a la constitucionalidad del precepto. Así, en la STC 68/2005 (FJ 4) reitera lo ya manifestado en la STC 99/2004, en la que se despejaba toda duda de inconstitucionalidad:

33 STC 68/2005: "Desde la perspectiva de control que a este Tribunal corresponde, lo relevante en este caso, como señalamos en la STC 99/2004, de 27 de mayo (FJ 6), es que la recurrente en amparo, en el plazo determinado por el Tribunal Supremo, ha podido impugnar, como efectivamente hizo, los recursos del Ministerio Fiscal y del Abogado del Estado, formulando y proponiendo al respecto, al margen de su éxito o no en la vía judicial, cuantas alegaciones tuvo por conveniente y los medios de prueba que estimó oportunos en defensa de sus derechos e intereses sobre la cuestión fundamental planteada en los recursos, esto es, el carácter de agrupación electoral como continuadora o sucesora de hecho de partidos políticos judicialmente ilegalizados y disueltos (art. 44.4 LOREG)». 
"En efecto, el Tribunal declaró en la citada Sentencia, ante el reproche indirecto de inconstitucionalidad contra el referido precepto legal formulado por diversas agrupaciones electorales, que el mismo carecía de fundamento, 'pues al haber optado nuestro ordenamiento jurídico por el control jurisdiccional de los actos de proclamación de candidaturas y candidatos (STC 24/1990, de 15 de febrero, FJ 2), es inexcusable articular dicha revisión jurisdiccional con arreglo a las notas características de celeridad y perentoriedad, a fin de no malograr el curso del propio procedimiento electoral. Como este Tribunal señaló ya en la STC 93/1999, de 27 de mayo, y reiteró en la STC 48/2000, de 24 de febrero, 'el proceso electoral es, por su propio naturaleza, un procedimiento extremadamente rápido, con plazos perentorios en todas sus fases y tanto en su vertiente administrativo como en los recursos jurisdiccionales que se establecen para el control de regularidad de todo el proceso'. Basta con lo dicho - continúa la Sentencia - para despejar toda duda de inconstitucionalidad, por las razones que se aducen sobre el repetido art. 49 LOREG".

Pero a pesar de que la jurisprudencia parece ser clara en cuanto a esta cuestión, hubo un voto particular a las STC 85/2003 y 99/2004, en el que la Magistrada doña Emilia Casas Baamonde mostró su discrepancia cuando dijo: «No creo que la naturaleza del proceso electoral, determinante de las notas de celeridad y perentoriedad características del control jurisdiccional de los actos de proclamación de candidaturas y candidatos, despeje sin más los problemas de constitucionalidad del citado art. 49.5 en relación con el art. 44.4 LOREG ${ }^{34}$. $\mathrm{Y}$, añadió que "la garantía judicial que el legislador ha incrustado en el comprimido calendario electoral (art. 49.5 LOREG) podría llegar a enervar la constitucionalmente necesaria tutela judicial efectiva sin indefensión....35.

El Tribunal Constitucional ha señalado a este respecto que el recurso de amparo electoral "aporta un nuevo cauce para una garantía jurisdiccional de los derechos fundamentales, entre los que se encuentran los derechos a la tutela judicial efectiva..." y ha reiterado que la brevedad de los plazos no afecta a este derecho $^{36}$, dado que "no implica per se una vulneración del derecho a la tutela judicial efectiva, si con ello se tiende a hacer efectivo el principio de celeridad

34 En el voto particular a la STC 99/2004 decía previamente: “debo expresar de nuevo mi disentimiento de la fundamentación recogida, básica aunque no únicamente en su fundamento jurídico 5, que reitera la contenida en el fundamento 9 de la STC 85/2003, de 8 de mayo, y de la que discrepé en el Voto particular a aquella Sentencia, a propósito de la constitucionalidad del proceso regulado en el art. 49 LOREG en relación con el supuesto de exclusión de candidaturas presentadas por agrupaciones electorales contemplado en su art. 44.4, dada la perentoriedad de los plazos establecidos para su tramitación y resolución".

35 Voto particular de la Magistrada doña María Emilia Casas Baamonde a la STC 85/2003.

36 La STC 68/2005 continúa en su FJ 4 como sigue: "... sin que pueda olvidarse, por lo demás, que la intervención del Tribunal Constitucional a través del recurso de amparo electoral, cuya especialidad ha sido resaltada en la STC 74/1986, de 3 de julio, aporta un nuevo cauce para una garantía jurisdiccional de los derechos fundamentales, entre los que se encuentran los derechos a la tutela judicial efectiva y al proceso debido (...) (destacando) la peculiaridad del amparo electoral en los supuestos del art. 49.4 LOREG, en los que la singularidad de la cuestión planteada ha de conducir a una flexibilización de los límites propios del recurso de amparo a la vista de la brevedad de los plazos del proceso previo, brevedad exigida por los fines del proceso electoral global (FJ 9)". 
en el proceso, pues es constitucionalmente inobjetable que el legislador prevea tal reducción en los plazos cuando tal decisión responde a una finalidad razonable y necesaria acorde con los principios que han de regir el procedimiento correspondiente (SSTC 14/1992, de 10 de febrero, FJ 8; 335/1994, de 19 de diciembre, FJ 3; y 130/1998, de 16 de junio, FJ 5),37 (Lo que aparece en cursiva se incorpora en la STC 68/2005).

Cabe pues, concluir, que la brevedad de los plazos no parece razón suficiente para declarar la inconstitucionalidad del art. 49 LOREG. En el ordenamiento jurídico español existen otros supuestos de brevedad de plazos, sin que se haya planteado la inconstitucionalidad de los correspondientes preceptos ${ }^{38}$. Cosa distinta es que se pueda plantear la conveniencia de su ampliación.

\section{EL DERECHO A LA INTIMIDAD EN RELACIÓN CON LA LEGISLACIÓN DE PROTECCIÓN DE DATOS PERSONALES}

La agrupación de electores demandante de amparo, Aukera Guztiak, alega que se ha producido una vulneración del derecho a la intimidad (en relación con la legislación de protección de datos) al entender que sus avalistas han sido objeto de un tratamiento masivo de datos personales por razón de su ideología. La demandante sostiene que "lo que realmente se ha estado investigando en este caso es la ideología y actividades de quienes ejercieron un derecho particular, no público, cual es el de, por medio de su firma, permitir que quienes se presenten en una lista electoral puedan concurrir a las elecciones "39.

El Tribunal Supremo, tras recordar que, como norma general, "el derecho fundamental a la protección de datos (art. 18.4 CE) faculta a los ciudadanos para oponerse a que determinados datos personales sean utilizados para fines distintos de aquel legítimo que justificó su obtención...." ${ }^{40}$, se remite a diferen-

37 La STC 68/2005, en su FJ 4 continúa diciendo: «el legislador ha configurado el proceso electoral, de acuerdo con su naturaleza, como 'un procedimiento extremadamente rápido... que exige plazos perentorios en todas sus fases, tanto en su vertiente administrativa, como en su vertiente jurisdiccional, y por lo tanto, requiere de todos los intervinientes (también por supuesto del órgano judicial) una extremada diligencia, puesto que se ha decidido hacer compatible el derecho a la tutela judicial efectiva de los recurrentes, con la necesidad de cumplir los plazos establecidos para, a su vez, cumplir los de la globalidad del proceso electoral correspondiente" (FJ 10).

38 Por ejemplo, en la LECrim., se establece: "Los recursos de reforma o de súplica se interpondrán en el término de los tres días siguientes al en que se hubiere practicado la última notificación a los que sean parte en el juicio" (art. 211); mientras que el recurso de reforma ha de ser resuelto por el Juez "al segundo día de entregadas las copias" (art. 222). La LO 2/1980, de 18 de enero, sobre la regulación de las distintas modalidades de referéndum, al ocuparse de las reclamaciones y recursos establece en el art. 19: "1. Contra los acuerdos de las Juntas podrán interponerse los recursos o impugnaciones previstos en la legislación electoral general (...) 3. El recurso contenciosoelectoral se interpondrá ante la Junta que hubiere adoptado el acuerdo objeto del mismo, en el plazo de cinco días siguientes a su adopción".

39 STC 68/2005, de 31 de marzo (antecedentes).

40 STS de 26 de marzo de 2005 (FJ 9), continúa: “... y persigue garantizar a las personas un poder de control sobre sus datos personales, sobre su uso y destino, con el propósito de impedir su 
tes resoluciones en las que el Tribunal Constitucional ha analizado la protección de datos en relación con los procesos electorales. Estas sentencias coinciden en que no se ha producido la vulneración del derecho a la intimidad, fundamentalmente porque se trata de datos que no afectan a la vida privada, sino que forman parte de un proceso público, como es el proceso electo$\mathrm{ral}^{41}$.

El Tribunal Constitucional mantiene que el derecho de participación política implica, generalmente, una renuncia a mantener esa esfera de la vida privada oculta del conocimiento público, ya que «el carácter público que la legislación electoral atribuye a determinadas actuaciones de los ciudadanos en los procesos electorales, en concreto, la publicación de las candidaturas presentadas y proclamadas en las elecciones (...) tales datos son de conocimiento público, y frente a su publicidad no pueden esgrimir un pretendido derecho a la intimidad aquellos ciudadanos que libremente hayan decidido presentarse a las elecciones" ${ }^{42}$.

No obstante, y como advierte el Alto Tribunal, esta jurisprudencia no es aplicable al caso concreto que nos ocupa, pues el sujeto del derecho a la intimidad es diferente en este caso. No se trata de personas que se presentan voluntariamente para formar parte de un proceso público, sino de avalistas que tan solo prestan su firma en apoyo de una candidatura concreta. Así, el Tribunal Constitucional, en esta sentencia 68/2005 (FJ 15), tras determinar que no es posible, desde el punto de vista constitucional dar a los avalistas el alcance que les otorga el Tribunal Supremo, recuerda lo ya sentado en su jurisprudencia respecto a que «quien participa por decisión propia en un procedimiento público (...) no puede invocar su derecho fundamental a la intimidad personal ni la garantía frente al uso de la informática (art. 18.1 y 4 $\mathrm{CE}$ ), por el mero hecho de que los actos del procedimiento en los que deba figurar su nombre sean, por mandato de la Constitución o con apoyo de ella, objeto de publicación oficial o de la publicidad y accesibilidad que la trascendencia del propio procedimiento en cada caso demande", para concluir que "la publicidad y accesibilidad general de los nombres de quienes integran una candidatura electoral o de quienes han ejercido o ejercen un cargo público son del todo distintas a las que corresponden a quienes firman como avalistas en el procedimiento de constitución de una agrupación de electores, pues tales firmas de aval no son objeto en el procedimiento electoral, atendida su función, de un acto de publicación general ni de publicidad parango-

tráfico ilícito y lesivo para la dignidad y derecho del afectado". Ver también SSTC 292/2000, de 30 de noviembre (FJ 6) y 99/2004 (FJ 13).

41 Se refiere a las STC 85/2003 (FJ 21) y 99/2004 (FJ 13).

42 STC 85/2003, de 8 de mayo (FJ 21), dice previamente: "Las informaciones protegidas frente a una publicidad no querida corresponden únicamente a los aspectos más básicos de la autodeterminación personal (...). Y es obvio que entre aquellos aspectos básicos no se encuentran los datos referentes a la participación de los ciudadanos en la vida política, actividad que por su propia naturaleza se desarrolla en la esfera pública de una sociedad democrática, con excepción del derecho de sufragio activo dado el carácter secreto voto". 
nable a la que corresponde, por razones obvias, a las propias listas de candidatos" ${ }^{43}$.

Como puede observarse, la jurisprudencia constitucional sigue una línea coherente y continua en todas sus resoluciones referidas a la intimidad en relación con la legislación de protección de datos. Podemos decir que, mientras que aquellos que se presentan voluntariamente a unas elecciones renuncian a que se mantengan en secreto ciertos datos que afectan a su persona - que no a su intimidad-, no ocurre lo mismo con aquellos que participan en este tipo de proceso bajo categorías diferentes, como es el caso de los avalistas, y que no formarán parte de la vida pública.

\section{VI. ¿QUÉ SUPONE EL SILENCIO O LA AUSENCIA DE CONDENA COMO RESPUESTA A LOS ATENTADOS TERRORISTAS?}

Por último, cabe destacar la referencia que tanto el Tribunal Supremo como el Tribunal Constitucional hacen a la ausencia de condena del terrorismo por parte de la agrupación de electores Aukera Guztiak. Si bien es cierto que ambos tribunales se pronuncian a favor de que a ningún ciudadano se le puede exigir, por principio, hacer declaraciones de adhesión o repulsa sobre cualquier tema si éstas no "nacen" de su libertad de expresión ${ }^{44}$, también coinciden en que tratándose de una agrupación electoral sobre la que se cierne "sospecha fundada de connivencia con el terror o con formaciones que han sido proscritas en razón de esa connivencia, pueda esperarse de ella (...) una declaración inequívoca de distanciamiento, rechazo y

43 El Tribunal Constitucional advierte, además en este mismo fundamento jurídico y en relación con el problema de la continuidad, que aunque hubiera podido ser ésta (la identidad, filiación, etc. de los avalistas) una prueba válida para los tribunales, no habría sido suficiente para determinar la continuidad entre la agrupación de electores y los partidos políticos disueltos, y esto porque "No cabe (...) proyectar sobre la agrupación (sobre sus integrantes) sospechas a partir de apariencias o de indicios que surgen, su vez, de unas conductas (firmas aval) sobre las que la agrupación carece de control y que le son formalmente ajenas. En el caso extremo, una significativa presencia, entre los avalistas, de personas en su día ligadas a los partidos disueltos permitiría, tan solo, abrigar la conjetura de que tales personas ponen su confianza en la candidatura de la agrupación, pero a partir de esa conjetura no cabe construir aquí un indicio."

44 La STC 68/2005, FJ 16, reproduce de la STC 99/2004, FJ 19, lo que sigue: "Todo ello con independencia —decíamos a continuación — de que, si bien a ningún ciudadano se le puede exigir, por principio, manifestar adhesiones o repulsas que han de nacer solo, si lo hacen, de su libertad de expresión, es perfectamente aceptable en una sociedad democrática que, tan pronto se cierna sobre una agrupación electoral la sospecha fundada de connivencia con el terror o con formaciones que han sido proscritas en razón de esa connivencia, pueda esperarse de ella, si efectivamente no acepta más instrumentos que los del voto y el debate libre, una declaración inequívoca de distanciamiento, rechazo y condena de cuanto representan una organización criminal y sus instrumentos políticos; y ello por respeto, en primer lugar, a aquellos cuyo voto se busca para integrar, en su nombre, la voluntad del poder público. Con ello habría de bastar para deshacer la eficacia probatoria de indicios que, contra manifestación tan inconcusa, difícilmente podrían acreditar una realidad que así se desvirtúa”. 
condena de cuanto representan una organización criminal y sus instrumentos políticos" ${ }^{45}$.

La Sala del Art. 61 de la LOPJ del Tribunal Supremo, en su sentencia de 27 de marzo de 2003, dice al respecto que uresultan inconciliables con las exigencias constitucionales tanto las "conductas activas" (...) como las "declaraciones alternativas" (...), cuanto, en fin, las conductas "pasivas", caracterizadas por el silencio consciente, calculado y premeditado en las mismas circunstancias " ${ }^{46}$. Y continúa diciendo: "Una sociedad amenazada por el terror no es una sociedad libre, porque el terror se basa en la imposición por la violencia y el miedo de una opción minoritaria sobre las demás que conforman el carácter plural del proceso político e ideológico. (...) Ante la extraordinaria gravedad de los daños que el terrorismo y sus defensores producen a la sociedad en muertes y el dolor, pero también en términos de restricción de las libertades públicas y delimitación de la participación política, imponiendo a los adversarios políticos de los terroristas y sus cómplices el riesgo de su propia vida para poder participar en la vida pública, hay que aceptar como razonable, proporcional y adecuada la exigencia de que las organizaciones y agrupaciones que pretenden participar en las instituciones públicas realicen un rechazo inequívoco y concreto al terror ${ }^{47}$ (FJ 11).

45 Respecto a la no condena, en la STC 48/2003 (FJ 10), dice el TC: “...sin que nos corresponda ahora determinar si la mera ausencia de condena puede ser o no entendida como apoyo implícito al terrorismo, lo cierto es que la legitimación de las acciones terroristas o la exculpación o minimización de su significado antidemocrático y de la violación de derechos fundamentales que comportan pueden llevarse a cabo de modo implícito, mediante actos concluyentes, en determinadas circunstancias, siendo claro que, en tales supuestos, no puede hablarse de vulneración de la libertad de expresión".

46 STS de 26 de marzo de 2005 (FJ 6). En este sentido, la 13 de febrero de 2003 del Tribunal Europeo de Derechos Humanos (FJ Cuarto, apartado II, 1, A), dice: “...consideró la negativa de un partido político a condenar atentados terroristas como elemento de prueba en el proceso de su ilegalización, reseñando allí que resultan inconciliables con las exigencias constitucionales tanto "las conductas activas" que bajo el manto de aparente inocuidad del ejercicio de una legítima opción política esconden realmente una intención de colaboración con la actividad terrorista, prestando a ésta cobertura y justificación política, como las "declaraciones alternativas" a los comunicados de condena que ante un atentado terrorista suscriben la totalidad de los partidos políticos democráticos, cuanto, en fin, las conductas "pasivas", caracterizadas por el silencio consciente, calculado y premeditado en las mismas circunstancias".

47 En este mismo sentido se expresaba el Tribunal Constitucional en su sentencia 5/2004 (FJ 18) — citada por la STC 99/2004 (FJ 19)—, donde decía: "En un contexto de terrorismo, cuya realidad se remonta más de treinta años en el pasado, y en el que la legitimación del terror siempre se ha buscado por sus artífices desde el principio de equivalencia entre la naturaleza de las fuerzas enfrentadas, presentándose como única salida para la resolución de un pretendido conflicto histórico, inasequible a los procedimientos del Derecho, en ese contexto, decimos, la negativa de un partido a condenar un concreto atentado terrorista, como singularización inequívocamente buscada respecto a la actitud de condena de los demás partidos, adquiere una evidente densidad significativa por acumulación, pues se imbuye el significado añadido que le confiere su alineamiento en la trayectoria observada sobre ese particular por un partido que ha prodigado un entendimiento del fenómeno terrorista que, cuando menos, lo presenta como reacción inevitable a una agresión primera e injusta del Estado agredido por el terror". 
Como puede observarse, la jurisprudencia de los Tribunales Supremo y Constitucional es coincidente respecto al silencio o a la no condena de atentados terroristas por parte de ciertas formaciones políticas, en la línea de considerar que "la negativa de un partido político a condenar atentados terroristas puede constituir, en determinadas circunstancias, una actitud de 'apoyo político (...) tácito al terrorismo' o de legitimación de 'las acciones terroristas para la consecución de fines políticos', por cuanto esa negativa puede tener un componente cierto de exculpación y minimización del significado del terrorismo (...) En tanto que negativa de una expresión, como abstenerse de condenar acciones terroristas es también manifestación tácita o implícita de un determinado posicionamiento frente al terror ${ }^{48}$, además de que pronunciarse firmemente frente al terrorismo y sus métodos es "lo menos que cabe demandar de quien quiere servirse de los beneficios que brinda el sistema que la criminalidad quiere subvertir ${ }^{49}$.

No ocurre lo mismo con la doctrina, donde parece no haber un claro consenso. Por un lado, los autores que, como José Antonio Montilla Martos, consideran que esta conducta "no puede ser perseguida desde una perspectiva jurídico constitucional ${ }^{50}$ y, por otro, los que como Eduardo Vírgala Foruria, opinan que "la abstención ante el pronunciamiento de condena de actos de terrorismo que vaya a realizar un representante electo no es un apoyo tácito sino expreso al terrorismo" ${ }^{51}$

En cuanto a la validez probatoria de la no condena del terrorismo, parece haber cierta discrepancia entre los Tribunales Supremo y Constitucional. Así, mientras el Tribunal Supremo lo considera indicio que junto a otros puede llegar a confirmar la continuidad de Aukera Guztiak de los partidos ilegalizados ${ }^{52}$, el

48 Sentencia de la Sala Especial del art. 61 de la LOPJ (FJ 6) recoge estas palabras de la STC 5/2004 (FJ 18)

49 STC 99/2004 (FJ 19)

50 MONTILLA MARTOS, José Antonio, "Algunos cambios en la concepción de los partidos. Comentario a la STC 48/2003, sobre la Ley Orgánica 6/2002, de partidos políticos", en Teoría y Realidad Constitucional, núm. 12-13, 2004, pág. 571, dice: "A mi juicio, el Tribunal debería haber afirmado con claridad que la "no condena" no puede ser perseguida desde una perspectiva jurídicoconstitucional en cuanto el ordenamiento no juzga actos internos, que son garantizados por la libertad ideológica (art. 16.2 CE). Sólo pueden extraerse consecuencias jurídicas de otras actuaciones vinculadas a la "no condena", que ya no son ejercicio de la libertad ideológica sino de la libertad de expresión, como los comunicados alternativos, exculpaciones, etc."

51 VÍRGALA FORURIA, Eduardo, "Los partidos políticos ilícitos tras la LO 6/2002", en Teoría y Realidad Constitucional, núm. 12-13, 2004, págs. 251 y 252, continúa diciendo: "Este tipo de abstenciones no hay que compararlas con las posturas que puede adoptar un ciudadano, amparado por las libertades ideológica y de expresión, al ser requerido a contestar si es partidario de las acciones terroristas, ya que las de los representantes públicos no sólo manifiestan una posición ideológica determinada que deba conocer la opinión pública sino que van acompañadas de propuestas alternativas justificadoras de los actos terroristas y dirigidas a que desde las instituciones se eluda el pronunciamiento sobre la violencia terrorista".

52 STS de 26 de marzo (FJ 11): "Coincide así la actitud adoptada por los candidatos de AUKERA GUZTIAK con la mantenida tradicionalmente por los partidos ilegalizados (...), en acatamiento de las órdenes concretas cursadas por la organización terrorista ETA, cuyos dirigentes se han negado sistemáticamente a condenar el terrorismo (...)". 
Tribunal Constitucional estima que no puede considerarse prueba suficiente para determinar que existe una continuidad entre la agrupación de electores y los partidos ilegalizados. En este sentido, la STC 68/2005 dice: "La negativa a condenar expresamente el terrorismo no es, por tanto, indicio bastante para acreditar per se una voluntad defraudatoria como la contemplada por el art. 44.4 LOREG. Más bien sucede que su contrario, la condena inequívoca, constituye un contraindicio capaz de desacreditar la realidad de una voluntad de ese cariz deducida a partir de indicios suficientes. Basta con constatar aquél que el Tribunal Supremo ha entendido, de manera razonable y fundada, que la genérica condena de la violación de los derechos humanos por parte de la actora no alcanza a operar en este caso como contrapeso suficiente a los fines de desvirtuar tales indicios.... ${ }^{53}$.

\section{RECAPITULACIÓN: EL ESTADO DE LA JURISPRUDENCIA CONSTITUCIONAL}

Analizada esta sentencia y teniendo en cuenta aquellas otras en las que el Tribunal Constitucional se pronunció sobre ilegalización de partidos políticos y la continuación de éstos mediante agrupaciones de electores, parece indudable que el Alto Tribunal ha mantenido una clara línea jurisprudencial coincidiendo en la mayoría de sus argumentaciones con el Tribunal Supremo. Es de agradecer que exista una jurisprudencia coherente y coincidente, pues nos encontramos ante cuestiones de gran trascendencia. Hay que tener en cuenta que nos referimos a temas muy controvertidos y, tanto social como políticamente, preocupantes. Los demandantes de amparo pretenden ocultar, tras el supuesto ejercicio de ciertos derechos fundamentales, una intención defraudatoria, como es la de constituirse en una agrupación de electores para continuar a un partido ilegalizado por motivos de terrorismo.

El ejercicio del derecho a participar en los asuntos públicos. En ningún caso se trata de privar del ejercicio de los derechos de participación política a los recurrentes en amparo. Lo que se pretende es evitar que se haga un uso fraudulento de los derechos de participación política, provocando la desvirtualización de éstos y, por ende, de la democracia. No podemos olvidar que nos encontramos ante el caso de una agrupación de electores que, haciendo uso de los privilegios que nos otorga un sistema democrático como el nues-

53 Continúa el FJ 16 de la STC 68/2005, como sigue: "En otros términos, la Sentencia recurrida discurre en el marco de la jurisprudencia que acabamos de citar, al constatar la inexistencia de una condena del terrorismo, el cual no es lamentablemente una mera abstracción, sino una realidad concreta, perfectamente definida, ante la que no tiene el mismo valor significativo la condena genérica de la vulneración de los derechos civiles y políticos de cualquiera, que es la única a la que se refiere la recurrente y a la que es atribuible un cierto sentido de abstracción, que la condena concreta del terrorismo, que implica un referente subjetivo mucho más preciso, y que de existir constituiría el contraindicio referido en nuestra jurisprudencia". 
tro, pretende continuar a un partido político ilegalizado por motivos de terrorismo. No se intenta anular ninguna ideología, sino de evitar que lleguen al poder aquellos que defienden posturas favorables al terrorismo y al uso de la violencia indiscriminada. Razón por la que se considera que es legítimo que los poderes públicos establezcan los "mecanismos de garantía institucional" necesarios para evitar que se produzca este tipo de situaciones fraudulentas.

La brevedad de los plazos. Se considera que la brevedad de los plazos se justifica por las características propias del proceso electoral. No cabe duda de que el mismo precisa de gran celeridad, por lo que parece proporcionado que los tiempos establecidos para la interposición de los recursos sean cortos. Se constata, además, que en todos los casos ha habido tiempo suficiente como para presentar las alegaciones pertinentes, por lo que nada cabe decir respecto de la constitucionalidad de la norma. Cosa distinta es que se pudiera plantear la ampliación de dichos plazos pero, como ya se ha apuntado con anterioridad, no es éste el único caso en el que se exige una respuesta rápida sin que se haya planteado nunca la posibilidad de que los preceptos que así lo establecen sean inconstitucionales.

El derecho a la intimidad. No cabe duda de que hay ciertos datos que afectan a parcelas íntimas de nuestras vidas que merecen una especial protección, en el sentido de que su publicidad depende, sólo, de la voluntad del afectado; ninguna vacilación respecto a que la Ley prohíbe que los datos personales se vean inmersos en un tratamiento masivo, máxime cuando se trata de datos que afectan a las ideologías. Tampoco se aprecian discrepancias a la hora de determinar que cuando una persona se presenta voluntariamente a un proceso público, como es el electoral, renuncia a que ciertos datos privados (que no íntimos) se mantengan en secreto, lo que no afecta a su intimidad en absoluto. Hay que advertir, no obstante, que habrá que ser cuidadosos a la hora de determinar quiénes son esos sujetos que se entiende renuncian a ciertas parcelas de dicho derecho a cambio de entrar a formar parte de la vida pública. En este caso, a pesar de apreciarse cierta discrepancia entre ambos Tribunales, estimo que lo oportuno es, siguiendo la jurisprudencia constitucional, considerar que esta renuncia puede predicarse de los candidatos pero no de otras personas que, sin tener ni pretender una proyección pública, apoyan una lista electoral o a una formación política concreta.

El silencio o la ausencia de condena como respuesta a los atentados terroristas. Para concluir quisiera referirme al polémico tema de la ausencia de condena a los atentados terroristas. No hay duda sobre la interpretación que hacen los Tribunales, pero como se ha visto, en la doctrina sí se encuentran posturas discrepantes. Lo que parece claro es que el silencio, por sí solo, no puede ser considerado prueba irrefutable de apoyo al terrorismo a no ser que vaya acompañado de otro tipo de actos o expresiones. La cuestión es si se puede o se debe exigir a los representantes políticos este tipo de declaraciones. Los Tribunales coinciden en que sí, porque no se puede tratar una cuestión de tal envergadura al margen de los acontecimientos políticos y los problemas de te- 


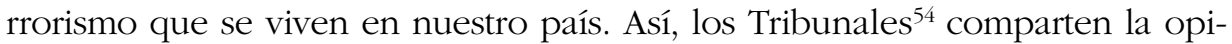
nión de que mientras a una persona privada no se le pueden exigir manifestaciones de ningún tipo que no nazcan de su libertad de expresión, "hay que aceptar como razonable, proporcional y adecuada la exigencia de que las organizaciones y agrupaciones que pretenden participar en las instituciones públicas realicen un rechazo inequívoco y concreto al terror ${ }^{55}$.

54 STS de 27 de marzo de 2003 y en el mismo sentido SSTC 5/2004 y 99/2004.

55 Me parece oportuno apuntar que al finalizar estas notas, se ha producido una noticia relacionada con el trabajo realizado. Se trata de la admisión a trámite de una querella contra el Partido Comunista de las Tierras Vascas, por su supuesta vinculación con ETA. Así, El Mundo de 12 de julio de 2005 recoge: «El juez de la Audiencia Nacional Fernando Grande-Marlaska acordó admitir a trámite la querella que la Asociación de Víctimas del Terrorismo interpuso contra el PCTV e investigar a este partido por colaboración con ETA". 